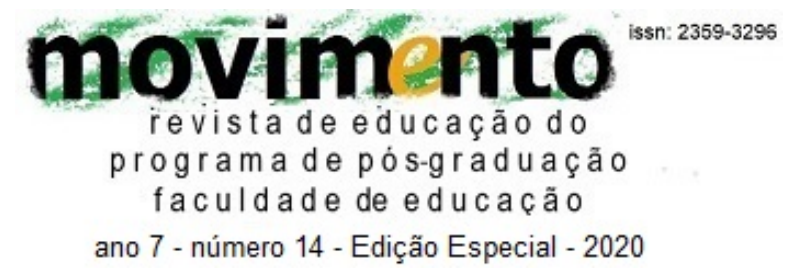

\title{
OS DEBATES SOBRE A FORMAÇÃO DOCENTE NA CAPES E NA ANPEd (2016-2019)
}

\author{
Adilson de Souza Borges \\ Universidade do Oeste de Santa Catarina (UNOESC) \\ Joaçaba, SC, Brasil \\ DOI: https://doi.org/10.22409/mov.v7i14.43925
}

\begin{abstract}
RESUMO
O artigo tem por objetivo evidenciar os principais temas candentes debatidos recentemente acerca da formação docente no campo das políticas educacionais a partir das produções cientificas do Portal de Periódicos Capes e da Associação Nacional de Pós-Graduação e Pesquisa em Educação (ANPEd) entre 2016 e 2019. Para tanto, desenvolvemos uma pesquisa qualitativa de análise de conteúdo, beneficiando-se dos trabalhos das obras de Vieira (2002), Behring (2008), Flick (2013), entre outros autores. Os resultados apontam para os seguintes temas: Profissionalização e a construção da identidade docente; As políticas de mercado e a regulação da atividade docente; Formação para a Educação Inclusiva; Valorização docente na Educação Básica; Valorização da Educação Infantil; Constituição de espaços formativos para a aprendizagem docente; Autonomia e saberes docentes nas práticas pedagógicas; Articulação entre a escola e a universidade e o PIBID; Expansão do Ensino Superior.
\end{abstract}

Palavras-chave: Formação docente. Políticas educacionais. Temas candentes.

\section{THE DEBATES ABOUT THE TEACHING TRAINING IN THE CAPES AND ANPEd (2016-2019)}

\begin{abstract}
The article aims to highlight the main current topics recently discussed about teacher education in the field of educational policies from the scientific productions of the Portal de Periódicos Capes and the Associação Nacional de Pós-Graduação e Pesquisa em Educação (ANPEd) between 2016 and 2019. For this purpose, we developed a qualitative research of content analysis, benefiting from the works of Vieira (2002), Behring (2008), Flick (2013), among other authors. The results point to the following themes: Professionalizin $0 \mathrm{~g}$ and the construction of teaching identity; The Market policies and the regulation of educational activity; Training to the Inclusive Education; Teaching appreciation in the basic schooling; Early Childhood Education appreciation; Constitution of formative spaces for the teaching learning; Autonomy and teaching knowledge in the pedagogical practices; Articulation
\end{abstract}




\section{movim nto \\ programa de pós-graduação \\ faculdade de educação \\ ano 7 - número 14 - Edição Especial - 2020}

between the school and the university and the PIBID; Expansion of Higher Education.

Keywords: Teaching Education. Educational Policies. Current Themes.

\section{LOS DEBATES SOBRE FORMACIÓN DOCENTE EN CAPES Y ANPEd (2016-2019)}

\section{RESUMEN}

El artículo tiene como objetivo resaltar los principales temas candentes recientemente discutidos sobre la formación de docentes en el campo de las políticas educativas de las producciones científicas de las revistas de Portal de Periódicos Capes y Associação Nacional de Pós-Graduação e Pesquisa em Educação (ANPEd) entre 2016 y 2019. Para este propósito, desarrollamos una investigación cualitativa de análisis de contenido, beneficiando las obras de Vieira (2002), Behring (2008), Flick (2013), entre otros autores. Los resultados apuntan a los siguientes temas: profesionalización y construcción de la identidad docente "; "Políticas de mercado y regulación de la actividad docente"; "Capacitación para la educación inclusiva"; "Apreciación del profesorado en educación básica"; "Valoración de la educación de la primera infancia"; "Formación de espacios de formación para la enseñanza del aprendizaje"; "Autonomía y conocimiento docente en prácticas pedagógicas"; "Articulación entre escuela y universidad y PIBID"; "Expansión de la educación superior".

Palabras clave: Formación docente. Políticas educativas. Temas de actualidad.

\section{Introdução}

Este estudo se propõe a refletir sobre alguns temas debatidos nos últimos 3 anos no contexto da formação docente e das políticas educacionais. Para tanto, as discussões serão realizadas a partir de uma perspectiva teórica com base em Vieira (2002) e Krawczyk (2008) e da constituição de material empírico com abordagem qualitativa (ESTEBAN, 2010) utilizando as orientações da análise de conteúdo (FLICK, 2013).

Neste sentido, o material bibliográfico que iremos apresentar aponta para inúmeros desafios que a formação docente no Brasil ainda precisa superar. Por isso, o presente estudo dedica-se em evidenciar os principais temas candentes debatidos recentemente acerca da formação docente no campo das políticas educacionais a partir das produções cientificas do Portal de Periódicos Capes 


\section{movim nto \\ programa de pós-graduação \\ faculdade de educação \\ ano 7 - número 14 - Edição Especial - 2020}

(Coordenação de Aperfeiçoamento de Pessoal de Nível Superior) e no site da ANPEd entre os períodos de 2016 e 2019, a fim de compreender os avanços e limitações, contribuindo com as discussões e a produção de novos conhecimentos.

Os resultados apontam para os seguintes temas candentes: Profissionalização e a construção da identidade docente; As políticas de mercado e a regulação da atividade docente; Formação para a Educação Inclusiva; Valorização docente na Educação Básica; Valorização da Educação Infantil; Constituição de espaços formativos para a aprendizagem docente; Autonomia e saberes docentes nas práticas pedagógicas; Articulação entre a escola e a universidade e o PIBID; Expansão do Ensino Superior.

\section{As políticas educacionais.}

A educação brasileira tem demonstrado algumas tendências marcantes nos últimos anos que consequentemente nortearam as políticas de formação docente, materializando-se sobretudo através das reformas na educação. Neste sentido, a compreensão das políticas sociais é fundamental para entender como e/ou por que ocorrem o desenvolvimento de determinadas ações, das disputas entre as forças sociais e dos movimentos que influenciam as reformas educacionais (VIEIRA, 2002).

De acordo com Vieira (2002, p. 14), "o Estado é uma referência fundamental" para a compreensão das políticas educacionais, pois atua "por meio de iniciativas direta ou indiretamente promovidas pelo poder público" através de um processo complexo que envolvem negociações, disputas entre os grupos sociais e, por fim, a elaboração da legislação oficial. Neste viés, é comum o poder público (União, estados e municípios) travar o jogo minimizando as influências dos demais atores sociais operando "como única instância de formulação política" (VIEIRA, 2002, p, 15).

Portando, destacamos que as políticas educacionais são constituídas a partir de interesses que possuem orientações bem definidas, intenções políticas, econômicas e sociais, com o objetivo de projetar um modelo de formação para a 


\title{
movim nto \\ programa de pós-graduação \\ faculdade de educação \\ ano 7 - número 14 - Edição Especial - 2020
}

sociedade e a "uniformização do sistema escolar" através da legislação educacional (BELLO, 2002, p. 63).

\subsection{Políticas, reformas e a formação docente}

A legislação educacional além de atuar como um instrumento de uniformização do sistema escolar também opera na regulamentação dos currículos da formação docente, determinando às instituições de ensino a priorização de um mínimo curricular em suas grades e, por conseguinte catalisando uma formação mais homogênea e sistematizada. Neste processo, cabe destacar que toda atividade formativa possui um embasamento teórico (científico, filosófico e/ou ideológico) inserido em um contexto político, social e econômico, que por sua vez, influenciam significativamente na formação e no trabalho docente (BELLO, 2002). Sendo que, esse contexto por vezes manifesta algumas mudanças (e/ou alterações) que consequentemente influenciam nas orientações políticas materializando-se através de reformas educacionais e da formação docente.

$\mathrm{Na}$ década de 90 por exemplo, a partir da LDB 9.394/1996 ocorreram reformas significativas na organização e gestão das escolas e do sistema educacional. Segundo Krawczyk (2008, p. 47)

\begin{abstract}
No ideário da reforma buscava-se conciliar as diretrizes internacionais para a constituição de uma nova forma de gestão da educação e da escola, no marco de mudanças regulatórias próprias do novo modelo hegemônico do papel do Estado, e a premente necessidade de reverter o quadro de exclusão e desigualdade educacional, representado principalmente pelo exíguo atendimento à demanda do ensino fundamental e médio e dos altos índices de fracasso escolar.
\end{abstract}

Neste sentido, observa-se que houve influência internacional significativa em nossas políticas e legislação educacional. Essa conciliação buscou imprimir um novo modelo de gestão e do papel do Estado condicionando todo um sistema educacional a partir de uma concepção de qualidade e modernização.

Para tanto, o Estado articulou através da legislação o controle do sistema educacional por meio da definição de diretrizes e avaliações, organizando todo o sistema escolar, fomentando a municipalização do ensino fundamental e desenvolvimento de parâmetros curriculares e métodos de avaliação da Educação 


\section{movim nto \\ programa de pós-graduação \\ f a culdade de educ a ção \\ ano 7 - número 14 - Edição Especial - 2020}

Básica. Ainda, ampliou "a responsabilidade dos estados e municípios sobre a gestão e o provimento da educação à população em todos os níveis" embora atuando em regime de colaboração (KRAWCZYK, 2008, p. 53).

Elaine Behring (2008) corrobora o argumento de Krawczyc preconizando que essas reformas educacionais ocorridas na década de 90 foram influenciadas por um processo de adaptação "às requisições do capitalismo mundial", isto é, do contexto econômico, social e político predominante. Noutras palavras, foi uma tentativa de reconfigurar o papel do Estado sob a ótica neoliberal (KRAWCZYK, 2008, p. 113).

Contribui para este argumento Ferreira e Oliveira, destacando que em nome da "modernização" os governos desenvolvem ações buscando fortalecer ainda mais um plano de sociedade que atenda as demandas de orientação capitalista e que tem na educação escolar algumas finalidades, tais como: a garantia e legitimação do sistema, a habilitação técnica e ideológica, a qualificação para o mercado de trabalho, a capacitação flexível para o desenvolvimento econômico, etc (FERREIRA; OLIVEIRA, 2009).

Além das reformas ocorridas a partir da década de 90 temos na atualidade a Base Nacional Curricular Comum (BNCC), que vem imprimindo novas transformações em todo o sistema escolar nacional. Com a BNCC os currículos escolares já obtiveram mudanças significativas e o programa disciplinar do Ensino Básico vem sendo modificado, sobretudo no Ensino Médio. Inclusive, alguns estudos anunciam algumas implicações pedagógicas no trabalho docente e a perda de autonomia do professor (FRANCO et al, 2018), a predominância do pensamento e projeto formativo neoliberal (NEIRA et al, 2016) e as ameaças do processo democrático em sua elaboração (MICARELLO, 2016). Portanto, podemos aguardar o desenvolvimento de novos processos formativos para atender as orientações da BNCC, a mudança da dinâmica do trabalho docente, do processo de ensino e aprendizagem escolar e as alterações na forma de gestão e orientação pedagógica.

É necessário evidenciar que durante os últimos anos, especialmente nos governos ditos populares, embora havendo diferentes avanços, sobretudo no 


\section{movim nto \\ revista de educação do \\ faculdade de educação \\ ano 7 - número 14 - Edição Especial - 2020}

acesso/expansão do ensino superior e a ampliação da educação profissional, esta lógica se confirmou, e em alguns aspectos se acentuou a partir de algumas legislações e ferramentas que "intensificaram mecanismos de controle e regulação do processo educativo da população brasileira", bem como coadunaram na predominância de uma formação docente caracterizada pela fragmentação e o esvaziamento teórico (RODRIGUES; COUTINHO, 2017, p. 900).

Cabe ressaltar, que de acordo com as produções bibliográficas aqui elencadas, o desprestigio da formação docente, a desvalorização, as péssimas condições de trabalho e a desqualificação profissional são diagnósticos atuais e gritantes da profissão docente que ainda não foram superados e/ou em alguns aspectos até inflamados nesses últimos anos mesmo com o desenvolvimento de diferentes reformas educativas.

Sobre os fatores que contribuem para o desenvolvimento das reformas educacionais, Vieira (2002, p. 20) desenvolve uma síntese apontando três fatores fundamentais que atuam nesses processos: "1) a consolidação do processo de globalização; 2) a redefinição da(s) forma(s) de organização do Estado; e 3) o fortalecimento do papel das agências internacionais".

A humanidade ingressou em um processo de economia global que revolucionou as produções e as relações entre os países, tornando-se um fenômeno econômico de abrangência social e cultural. Deste modo, novas regras econômicas, novos processos e negócios ditam o jogo a partir de uma revolução, sobretudo tecnológica, pautada na "informação e inovação" onde são desenvolvidas numa "escala planetária em tempo real", com reflexos na "organização da política global, regional e local" (VIEIRA, 2002, p. 21-22). Paralelamente, desdobrasse um processo de redefinição das formas de organização dos Estados nacionais, onde o Estado "passa a assumir uma posição de agente comercial do desenvolvimento, delegando a outros setores encargos que tradicionalmente lhe diziam respeito" (VIEIRA, 2002, p. 27). Por outro lado, somase a estes fatores o fortalecimento das agências internacionais que são um esteio fundamental na reorganização do estado e na globalização, patrocinando 


\section{movim nto \\ programa de pós-graduação \\ faculdade de educação \\ ano 7 - número 14 - Edição Especial - 2020}

programas de desenvolvimento e financiamentos, bem como acordos técnicos de cooperação e articulação/organização com diferentes organismos. Como é o caso da Unesco, como promotora de atividades de discussões, estudos e estabelecimentos de padrões, como exemplo o Fórum Mundial de Educação, e o Banco Mundial, destacando-se no financiamento de recursos à educação e a formação docente, "atingindo de forma direta a política educacional" (VIEIRA, 2002, p. 37).

Em suma, num exercício de análise podemos observar alguns desdobramentos materializados através de algumas políticas educacionais, tais como: a exigência de professores cada vez mais qualificados e/ou atualizados no PNE 2000-2010, as avaliações de desempenho a partir da LDB n 9.394/1996 "como um critério de progressão funcional" (VIEIRA, 2002, p. 38), a recentralização das políticas educacionais pela União, a formação docente mais curta e flexível, entre outras questões.

\section{Principais temas da pesquisa brasileira nos últimos três anos}

Para o desenvolvimento deste estudo utilizamos a abordagem qualitativa compreendendo a sua importância na realização de investigações dos diferentes fenômenos das ciências sociais e humanas, tendo em vista as possibilidades de práticas de procedimentos metodológicos possíveis a partir desta abordagem (ESTEBAN, 2010). Ademais, nos orientamos nos pressupostos de Uwe Flick para a análise de conteúdo do material empírico, visando constituir categorias de análise com base nos principais temas/assuntos abordados, buscando evitar "obscurecer a visão dos conteúdos" (FLICK, 2013, p. 140). Esse método de análise é bastante utilizado na descrição transparente das características gerais das mensagens.

\subsection{A constituição do material empírico}

Para a constituição do material empírico foram selecionados artigos constantes no Portal Periódicos Capes e no site da ANPEd, respectivamente datados de 2016 a 2019. Neste sentido, relativamente ao Portal Periódicos Capes, 


\section{movim nto \\ programa de pós-graduação \\ faculdade de educ a ção \\ ano 7 - número 14 - Edição Especial - 2020}

desenvolvemos uma busca avançada utilizando o descritor formação docente incidindo sobre o título, o resumo e as palavras-chave, como assunto o descritor educação e o intervalo de tempo de 2016 a 2019. Posteriormente, utilizamos um refinador de busca chamado de Periódicos revisados pelos pares e, por fim, a plataforma ainda propiciou um recurso denominado Refinar meus resultados onde encontramos, no dia 2 de janeiro de 2020, no item Formação docente um total de 47 trabalhos.

Relativamente a constituição do material empírico no site da ANPEd, primeiramente entramos no GT08 - Formação de Professores encontrando 23 artigos que compõem o conjunto das produções da reunião nacional do ano de 2017 realizada em São Luiz do Maranhão, contudo as produções de 2019 ainda não estavam disponíveis até meados de dezembro deste mesmo ano.

A partir daí, definimos como critério de exclusão os seguintes determinantes: artigos que não eram da área da educação, escritos em língua estrangeira e que não tratavam da temática formação docente. Assim, chegamos ao total de 52 artigos, 30 artigos dos Periódicos Capes e 22 artigos da ANPEd.

Por fim, realizamos a leitura crítica dos achados com incidência sobre o título, o resumo e as palavras-chave com o objetivo evidenciar os principais temas candentes debatidos recentemente acerca da formação docente no campo das políticas educacionais. Neste sentido, inicialmente buscamos identificar os diferentes assuntos presentes nos textos que apontavam para as temáticas das produções, bem como para as discussões abordadas. E, após, desenvolvemos uma tabela com os principais assuntos incididos em no mínimo 4 artigos, que posteriormente nos deram condições de identificar quais seriam os temas candentes emergentes. 


\section{movimento \\ programa de pós-graduação \\ faculdade de educação \\ ano 7 - número 14 - Edição Especial - 2020}

\begin{tabular}{|l|l|l|l|}
\hline \multicolumn{2}{|c|}{ ANPEd } & \multicolumn{2}{c|}{ Capes } \\
\hline Docência & 9 & Formação Continuada & 9 \\
\hline Formação Inicial & 7 & Prática & 8 \\
\hline Escola & 7 & Saberes docentes & 6 \\
\hline Aprendizagem & 7 & Educação Infantil & 5 \\
\hline $\begin{array}{l}\text { Desenvolvimento } \\
\text { profissional/Profissionalização }\end{array}$ & 5 & Formação Inicial & 5 \\
\hline Educação Básica & 5 & Políticas & 5 \\
\hline Universidade & 4 & & \\
\hline PIBID & 4 & & \\
\hline
\end{tabular}

Quadro 1: Incidência dos assuntos. Fonte: O Autor

A partir da identificação dos assuntos emergentes e consequentemente incidência nos artigos, encontramos um total de 42 artigos, 20 da ANPEd e 22 dos Periódicos Capes. A incidência dos assuntos é ilustrada nas imagens a seguir:

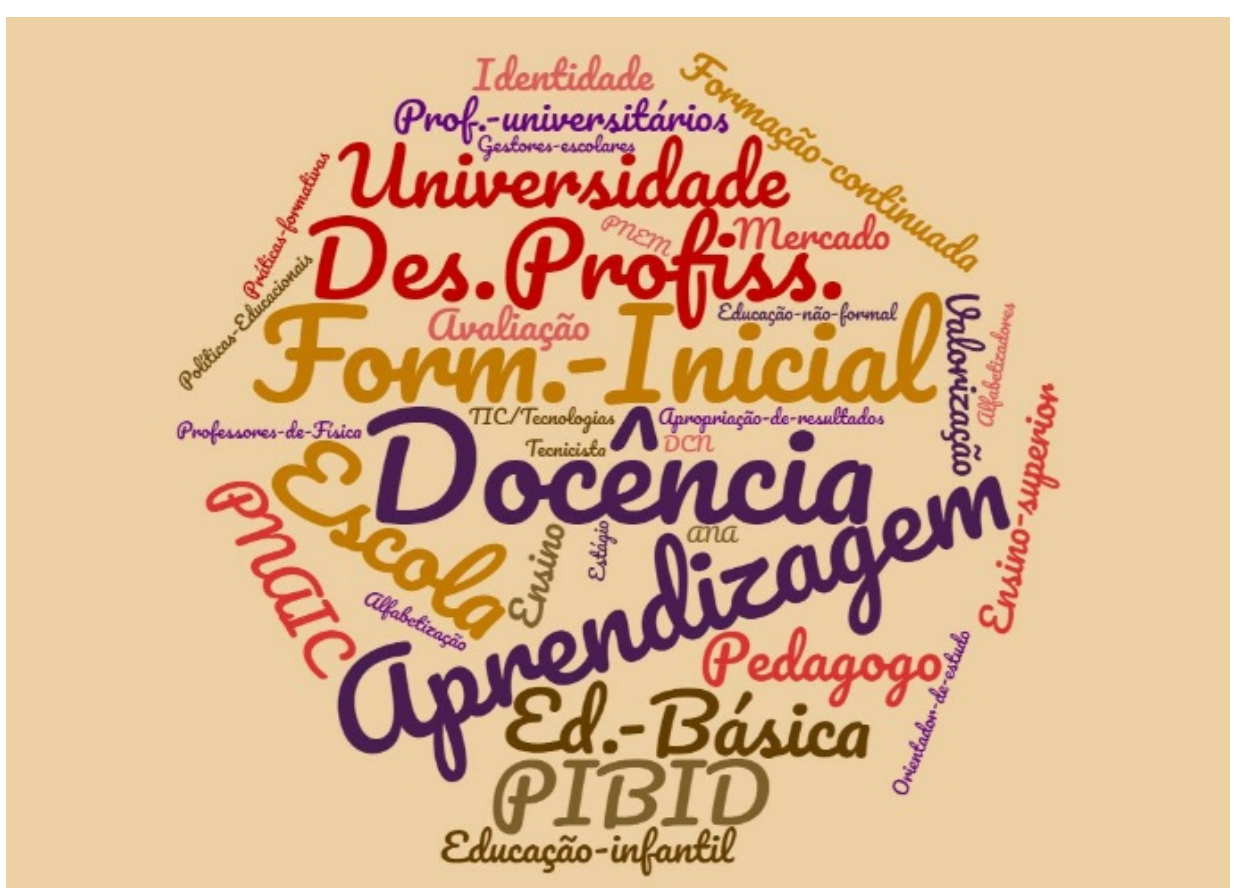

Imagem 1 - Assuntos incididos na Anped. Fonte: O Autor 


\section{movim nto \\ revista de educação do \\ programa de pós-graduação \\ f a culdade de educa ção \\ ano 7 - número 14 - Edição Especial - 2020}

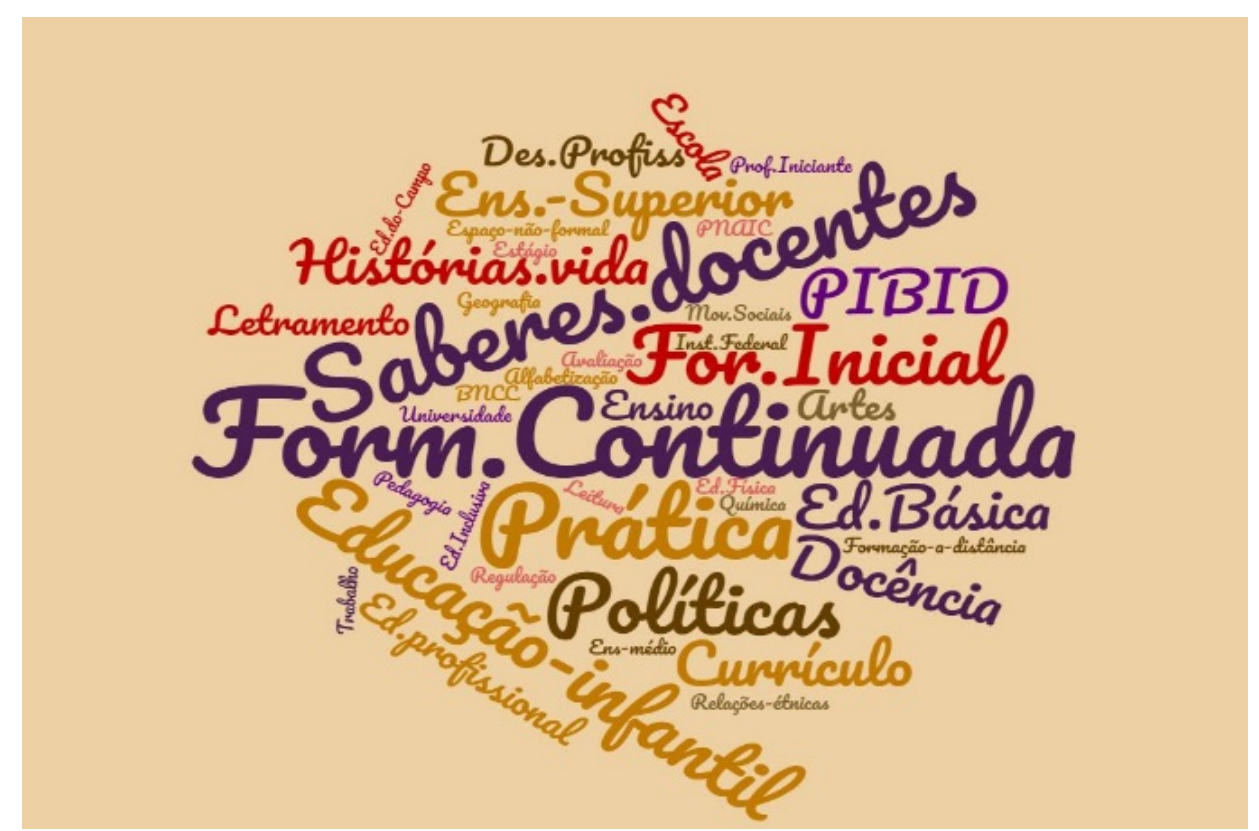

Imagem 2 - Assuntos incididos nos Periódicos Capes. Fonte: O Autor

Finalmente, desenvolvemos os recortes disciplinares de acordo com a incidência e aproximação dos temas/assuntos e iniciamos a leitura e análise de conteúdo na busca pela identificação dos temas candentes.

Recortes disciplinares:

1. Formação inicial e continuada, Des. Profissional/Profissionalização

2. Educação Básica, Educação Infantil, aprendizagem

3. Docência, prática, saberes docentes, PIBID

4. Escola, Universidade, políticas

\subsubsection{Formação inicial e continuada, Des. Profissional/Profissionalização}

Este recorte disciplinar se propõe a evidenciar os principais temas candentes relativos à formação inicial e continuada e o desenvolvimento profissional docente. Neste sentido identificamos que as produções apontam para discussões relativas as posturas imediatistas na formação docente, o desenvolvimento de processos formativos em espaços não escolares, a formação docente para a educação inclusiva e as contribuições do Programa Institucional de Bolsa de Iniciação à Docência (PIBID) e do Pacto Nacional pela Alfabetização na Idade Certa (PNAIC) como programas de apoio ao professor. 


\section{movimento \\ revista de educação do \\ programa de pós-graduação \\ faculdade de educação \\ ano 7 - número 14 - Edição Especial - 2020}

Relativamente as discussões sobre a formação com posturas imediatistas, Kurtz (2017, p. 14), aponta para a necessidade de abandonar uma concepção de formação docente "puramente instrumental e técnica no que diz respeito à utilização de TIC no processo de ensinar e aprender", ainda sugere a urgência do repensar a formação tendo o professor como um intelectual e não como agende de mercado. Por sua vez, o estudo de Rabelo (2017, p. 1) evidencia que os cursos de licenciatura em Pedagogia necessitam incluir em seus processos de formação os espaços não escolares e defende que o exercício da docência nesses ambientes, constituem-se possibilidades de inovação profissional e "alcança novos espaços de atuação do pedagogo".

Ao analisarem as produções cientificas nacionais relativas a formação docente no contexto da Educação Inclusiva relacionada ao público da Educação Especial, Silva e Martins (2016) sinalizam para "uma tendência a generalização", sendo que "a formação de professores especialistas tem sido pouco investigada", sugerindo como decorrência de uma crise de identidade profissional, caracterizada pela dicotomia entre generalidade $x$ especialidade.

Por sua vez, no que se refere a formação no contexto do PIBID, os artigos sinalizam que o programa é um instrumento que contribui na reformulação de posturas teóricas e do fazer docente (RODRIGUES; CARDOSO, 2017), bem como na melhoria da qualidade educacional e no fortalecimento da formação profissional (DOMINSCHEK; ALVES, 2017). Ainda, apontam que programas de apoio para professores iniciantes contribuem no desenvolvimento profissional minimizando "os desafios da iniciação docente" tal como para "a permanência na profissão" e o desenvolvimento de aprendizagem coletiva (HANITA, 2017, p. 1). Contudo, em relação ao PNAIC, foi destacado por Felipe que esse programa "foi incorporado pelos professores como uma política da perfomatividade, do desempenho e da quantificação de resultados", além disso assinala que não há reflexão da e/ou sobre a prática, e a participação docente nos planejamentos e definição de conteúdos é praticamente nula, favorecendo a cultura do isolamento e individualismo em sobreposição a um processo colaborativo (FELIPE, 2017, p. 12). 


\section{movim nto \\ programa de pós-graduação \\ f a culdade de educ a ção \\ ano 7 - número 14 - Edição Especial - 2020}

Já o estudo de Scartezini evidencia a proficuidade de trazer a luz as diferentes abordagens da construção teórica relativa a identidade profissional docente, elencando algumas discussões sobre as políticas de formação na pósgraduação e os "discursos das atuais reformas educativas" no contexto da construção da identidade profissional. Alerta para a "necessidade de investimento no desenvolvimento da identidade profissional de professores com diferentes níveis de experiência", bem como em novas propostas de formação que atendam "às novas demandas da docência" e que tenham ênfase no desenvolvimento de "aspectos não contemplados nas reformas educativas, porém cruciais para a sua efetividade" (SCARTEZINI, 2017, p. 12-13).

Pela observação desses diferentes aspectos, podemos destacar como temas candentes os debates em torno das políticas de Profissionalização e construção da identidade docente, As políticas de mercado na formação docente e a Formação para a Educação Inclusiva.

\subsubsection{Educação Básica, Educação Infantil, aprendizagem}

Neste recorte disciplinar apresentamos as principais discussões e, por fim, os temas candentes relativos a Educação Básica e Infantil e a aprendizagem docente. Desta forma, nota-se que as discussões caminham no sentido de evidenciar as políticas de avaliação e profissionalização docente da Educação Básica, bem como chamar a atenção para maiores investimentos na Educação Infantil e desenvolvimento de programas e construção de espaços de aprendizagem docente.

Relativamente a Educação Básica, as políticas de avaliação, formação docente e valorização profissional, articulação entre a Educação Básica e a Universidade estão entre as principais discussões levantadas pelas produções acadêmicas elencadas. Neste sentido, Guimarães; Henriques e Assis destacam que há "uma sensação de espaço profissional movediço que desponta diretamente na escassez de professores" (GUIMARÃES; HENRIQUES, 2017, p. 2) atuando na Educação Básica, "fenômeno em franco processo de agravamento" (ASSIS, 2017, 


\section{movim nto \\ programa de pós-graduação \\ faculdade de educação \\ ano 7 - número 14 - Edição Especial - 2020}

p. 1). Também, é evidenciado por Silva (2017, p. 4) sobre a necessidade de uma consistente articulação entre o Ensino Superior e a Educação Básica tendo em vista a construção de saberes docentes "relacionadas aos saberes da universidade e da educação básica", considerando a realidade de que muitos professores que atuam neste nível de ensino não possuem formação específica ou superior. Enfim, Rivelli (2017, p. 2) sinaliza para o crescimento de uma "cultura nacional de avaliação em larga escala" no Brasil, destacando o desenvolvimento de programas e/ou políticas de responsabilização docente. Além disso, propõe que para ter uma avaliação consistente é necessário a priori utilizar os resultados desses indicadores na atividade docente, formando um movimento que continuamente se retroalimenta.

A Educação Infantil também é um dos temas em destaque nas discussões das produções acadêmicas. Em geral, os trabalhos selecionados discorrem sobre as necessidades de maiores investimentos em processos formativos para este nível de ensino (SOUZA; DINIZ, 2018), bem como reconhecem a importância de movimentos sociais para a efetivação do exercício da docência na Educação Infantil (CANAVIEIRA, 2018). Do mesmo modo, é evidenciado a importância da autonomia docente para a "emancipação social, política e cultural" por parte das crianças, a necessidade de um maior protagonismo infantil no cotidiano de sala de aula e desenvolvimento de políticas públicas que atendam as demandas deste nível de ensino (SILVA, 2016, p. 93). Enfim, Carvalho (2019, p. 100) anuncia a predominância de uma "contingência dos discursos pedagógicos" resultando em práticas de governamento vinculadas nos livros da Educação Infantil e formação docente naturalizando o discurso da pedagogia histórico-crítica.

Sobre a aprendizagem, Bastos (2017) destaca o "museu como um lócus de formação", constituindo-se um rico espaço de educação não formal e de aprendizagem. No mesmo sentido, Martins et al (2017, p. 1) sustenta que a aprendizagem docente "não se limita a espaços educativos formais e tradicionais". Por sua vez, Hanita (2017) discute sobre a aprendizagem coletiva a partir de programas e/ou políticas de apoio a professores iniciantes, destacando que essas propostas contribuem para o desenvolvimento profissional do professor, 


\section{movim nto \\ programa de pós-graduação \\ f aculdade de educaçã 0 \\ ano 7 - número 14 - Edição Especial - 2020}

propiciando o compartilhamento de experiências, participação em diferentes processos formativos, práticas e contextos, constituindo-se em "espaço formativo de desenvolvimento profissional docente" (HANITA, 2017, p. 1). De conformidade, Campelo (2017) e Paniago (2017) evidenciam o PIBID como uma política que promove a aproximação entre a escola e a universidade potencializando a aprendizagem docente na formação inicial.

Em virtude do que foi apontado, observa-se que os temas candentes giram em torno das políticas de Avaliação da formação docente e valorização profissional na Educação Básica, a Valorização da Educação Infantil e a autonomia docente e a Constituição de espaços formativos para a aprendizagem docente.

\subsubsection{Docência, prática, saberes docentes, PIBID}

Discutimos neste recorte os principais temas candentes relativos a Docência, prática, saberes docentes e o PIBID. Assim, destacamos que os artigos buscaram problematizar sobre a iniciação à docência, sobre as políticas e agentes influenciadores, as práticas e saberes docentes que promovem a autonomia docente e desenvolvimento profissional e as contribuições do PIBID na formação docente.

Relativamente ao assunto docência, os artigos demonstraram alinhamento nas discussões sobre a iniciação à docência considerando-a como um tema emergente (ASSIS, 2017), também apresentam reflexões sobre a formação específica do professor para a docência, sobre as políticas nacionais de formação docente, bem como a influência externa e mercadológica na docência.

Nesta perspectiva, Paniago e Assis destacam que o PIBID é um programa que "tem contribuído significativamente para a aprendizagem da docência", oportunizando "a imersão em diversas atividades de aprendizagem" (PANIAGO, 2017, p. 1) e na "identificação dos licenciandos com a profissão docente" (ASSIS, 2017, p. 1). Por outro lado, Gomes evidencia a "reduzida formação específica para a docência", sobretudo na Educação Infantil (GOMES, 2017, p. 1), inclusive sinalizando para a predominância da mercantilização do ensino superior, bem como 


\section{movim nto \\ rograma de pós-graduaçã \\ faculdade de educação \\ ano 7 - número 14 - Edição Especial - 2020}

a pouca aproximação entre as disciplinas dos cursos analisados com a docência em ambiente escolar. Por fim, Rabelo (2017) manifesta que o exercício da docência em ambientes hospitalares, embora constitui-se em um desafio, também se demonstra uma oportunidade de inovação profissional.

Os artigos que versam sobre os assuntos práticas e saberes (docente) abordam aspectos voltados para as práticas inovadoras, pautadas em múltiplos saberes articulados com a teoria e os conteúdos, propiciando maior autonomia docente. Ademais, também oportunizam debates teóricos sob a perspectiva da BNCC. Deste modo, os trabalhos anunciam que as práticas inovadoras e significativas necessitam estar "pautadas na dimensão de múltiplos saberes com relações entre si" (PINHO; PASSOS, 2018, p. 433-434), tendo uma base teórica fortemente alicerçada para que a "prática docente seja mais coerente e consciente, de acordo com cada realidade pedagógica" (BARTHO; CLARO, 2018, 3412). Outrossim, destacam que essa articulação, bem como a natureza dos saberes contribuem para a reformulação de "posturas e teorias do fazer docente" (RODRIGUES; CARDOSO, 2017, p. 95), no protagonismo e autonomia do professor em sua atividade profissional (MARTINS FILHO; SOUZA, 2016) e ainda permitem revelar as características da sua formação (FERREIRA, 2017). Além disso, é problematizado sobre a necessidade de desenvolvimento de atividades formativas que coloquem em pauta a BNCC, tendo em vista a construção de saberes necessários a prática docente e que constituam "um novo olhar e um novo saber capazes de acolher a concepção de campos de experiência, transformandoa em práticas potentes e interessantes para as crianças" (LEAL et al, 2018, p. 112).

Sobre o PIBID, os artigos trataram de discutir sobre as suas contribuições e desafios relacionado a formação docente e a aproximação entre a escola e a universidade. Neste sentido, Campelo sinaliza que o PIBID, além de aproximar a escola da universidade também potencializa a aprendizagem docente através do "desenvolvimento de uma postura investigativa" (CAMPELO, 2017, p. 10). Contudo, é apontado nos trabalhos de Paniago e Cunha a "ausência de práticas efetivas dos formandos com alunos da educação básica, ausência de formação pedagógica dos 


\section{movim nto \\ programa de pós-graduação \\ faculdade de educação \\ ano 7 - número 14 - Edição Especial - 2020}

formadores e inexperiência com a investigação e ensino na educação básica" (PANIAGO, 2017, p. 1). Além disso, Cunha (2017, p. 9) destaca que "em alguns recortes discursivos os bolsistas de ID reproduziram o discurso que as formações discursivas autoritárias permitiram".

Portanto, analisando os assuntos elencados nesta categoria identificamos como temas candentes: a Formação para a docência, os Saberes docentes e práticas pedagógicas e as Contribuições e desafios do PIBID na formação docente.

\subsubsection{Escola, Universidade, políticas}

Neste recorte iremos discorrer sobre a Escola e a Universidade e sobre as políticas educacionais que apontam para a formação docente.

Relativamente a Escola e a Universidade, os artigos discutem sobre as relações e os desafios entre a escola e a universidade e as políticas de articulação no contexto da formação docente. A princípio, Arnosti (2017) identifica alguns entraves que dificultam esse processo, como por exemplo as influências da mídia, das organizações internacionais, entre outras questões. Já Rodrigues et al (2017), anuncia a falta de compreensão e esclarecimento sobre o que constitui uma parceria, bem como "a exiguidade de textos referentes à temática de estudo". Além disso, Campelo (2017) destaca a importância de programas como o PIBID na construção dessas relações e no desenvolvimento profissional docente. Enfim, a preocupação em relação a qualidade da educação escolar, a formação e o trabalho docente também são temáticas que permearam as discussões dos artigos.

Sobre as políticas, os artigos evidenciam discussões relativas as políticas de formação inicial, continuada e à distância, aos programas PIBID e PNAIC e sobre a Educação Profissional e a expansão do Ensino Superior. Desta forma, Oliveira Junior et al (2018, p. 52) verificou uma tendência de regulação profissional nas políticas de formação continuada, bem como "incentivos governamentais ou políticas públicas que possam impulsionar os programas de formação docente". Por sua vez, Faria et al (2016) evidencia os processos e políticas de expansão do Ensino Superior à distância no estado do Tocantins, anunciando um aumento 


\section{movim nto \\ programa de pós-graduação \\ f a culdade de educ a ção \\ ano 7 - número 14 - Edição Especial - 2020}

significativo da oferta de cursos à distância. Ademais, alguns estudos debatem sobre o papel do PIBID e do PNAIC como políticas públicas, exprimindo algumas contribuições do primeiro, contudo refletindo sobre alguns desafios e necessidades de articulação do segundo. Os trabalhos também levantaram discussões sobre a articulação entre a formação docente, avaliação e as políticas educacionais, sinalizando para "o descompasso entre a formação e as orientações legais vigentes" (VIDAL; VIEIRA, 2017, p. 64).

Enfim, Costa e Meneses Filho (2018, p. 1113) problematizando sobre as políticas da Educação Profissional constatam a predominância de uma "flexibilidade quanto a formação de professores", sendo que Araújo et al (2019, p. 176) anuncia a necessidade de desenvolvimento de "políticas públicas voltadas para a formação docente" de Artes para a atuação no estado do Tocantins.

Dado o exposto, entendemos que os principais temas candentes sobre as políticas abrangem a Articulação entre a escola e a universidade, a Regulação da formação docente, bem como a Expansão do Ensino Superior e as Políticas de formação docente.

\section{Análise do material empírico}

Buscamos no material empírico do estudo aspectos relacionados a discussão teórica desenvolvida no capítulo 2 com o objetivo de evidenciar os principais temas candentes. Nesse sentido identificamos diferentes aspectos que tem a ver com o papel do Estado como agente político, as políticas educacionais, influencias externas e de outras organizações na formação docente, dentre outras questões.

Um importante aspecto apontado na fundamentação teórica foi o desprestígio da formação docente e a desvalorização profissional, que ao nosso ver, produz o que Guimarães e Henriques (2017, p. 2) descrevem como um "espaço profissional movediço que desponta na escassez de professores" atuando na Educação Básica (ASSIS, 2017). Ademais, também mencionamos a tendência de 


\section{movim nto \\ programa de pós-graduação \\ faculdade de educação \\ ano 7 - número 14 - Edição Especial - 2020}

uma formação cada vez mais flexível (VIEIRA, 2002), que foi confirmada nos achados de Araújo et al (2019) e Costa e Meneses Filho (2018).

Por sua vez, é denunciado por Kurtz (2017) a predominância de posturas imediatistas, puramente instrumentais e técnicas na formação docente, anteriormente compreendidas por Bello (2002) como resultado da forte influência de alguns atores, em especial o mercado. Do mesmo modo, Felipe (2017) evidencia a predominância de políticas de performatividade e competição com foco em resultados demonstrando os efeitos de uma política educacional adaptada as requisições capitalistas neoliberais, onde buscamos problematizar em Krawczyk (2008).

Evidenciamos na problematização teórica e nos achados de Rivelli que a política educacional caracterizada pela avaliação em larga escala e a responsabilização docente (RIVELLI, 2017) exprimem a articulação do Estado na busca pelo controle do sistema educacional (KRAWCZYK, 2008) a partir de um viés liberal. Contudo, em contraste a essa realidade, Carvalho (2019, p. 100) manifesta em seu estudo a predominância de uma "contingência dos discursos pedagógicos", resultando em práticas de governamento vinculadas nos livros da Educação Infantil e de formação docente que naturalizam o discurso da pedagogia histórico-crítica que tem um viés ideológico distinto ao capitalismo, inclusive assumindo uma postura de denúncia a pedagogia liberal.

É importante ressaltar que alguns trabalhos problematizaram sobre a crise na formação docente, sobretudo a "reduzida formação específica para a docência" (GOMES, 2017, p. 1). Como também, sinalizaram para a necessidade de desenvolvimento de atividades formativas que tenham como ponto de partida (e de chegada) a realidade docente, bem como priorizem a construção "de múltiplos saberes com relações entre si" (PINHO; PASSOS, 2018, p. 433-434) e necessários para a reformulação de "posturas e teorias do fazer docente" (RODRIGUES; CARDOSO, 2017, p. 95). Para tanto, os autores vislumbram o estado como agente fundamental para essas mudanças, especialmente na construção de "políticas de formação de professores" (VIEIRA, 2002, p. 16). 


\section{movim nto \\ programa de pós-graduação \\ faculdade de educação \\ ano 7 - número 14 - Edição Especial - 2020}

As influências de organizações internacionais no processo de articulação entre a escola e a universidade também são elementos que foram anunciados por Arnosti (2017) e problematizados no capítulo anterior quando dialogamos com Vieira (2017). Essas organizações, em síntese tem dificultado esse processo. Ademais, também observamos a concordância entre a fundamentação teórica e o material empírico sobre a tendência de regulação profissional através das políticas de formação docente que visam intensificar mecanismos de controle do processo educativo (OLIVEIRA JUNIOR et al, 2018; RODRIGUES e COUTINHO, 2017).

\section{Considerações finais}

O diagnóstico da formação docente no Brasil é resultado de políticas públicas desastrosas e mal sucedidas que não foram eficazes na superação dos desafios e demandas educacionais. Dentre essas demandas podemos destacar o despreparo profissional docente e a dicotomia entre a formação e a realidade profissional que resultam no fracasso escolar manifestado através das avaliações da Educação Básica e evidenciados pela mídia.

Neste estudo buscamos identificar os temas candentes presentes em artigos da ANPEd e Capes entre os anos 2016 e 2019. Para tanto utilizamos a análise de conteúdo a partir da abordagem qualitativa de pesquisa. Assim, após a análise de 42 artigos identificamos os principais assuntos/temas emergentes a partir dos recortes disciplinares desenvolvidos. Enfim identificamos os principais temas candentes.

Para a compreensão teórica sobre o tema dialogamos especialmente com Vieira (2002) e Krawczyk (2008), discutindo sobre as políticas educacionais e as reformas na educação e na formação docente, que nos deram condições de identificar os temas atuais, os assuntos discutidos e os aspectos políticos problematizados.

Os achados apontam para os seguintes temas candentes: Profissionalização e a construção da identidade docente; As políticas de mercado e a regulação da atividade docente; Formação para a Educação Inclusiva; Valorização docente na 


\section{movim nto \\ programa de pós-graduação \\ faculdade de educação \\ ano 7 - número 14 - Edição Especial - 2020}

Educação Básica; Valorização da Educação Infantil; Constituição de espaços formativos para a aprendizagem docente; Autonomia e saberes docentes nas práticas pedagógicas; Articulação entre a escola e a universidade e o PIBID; Expansão do Ensino Superior.

Esse estudo deu um importante passo na medida que identificou as principais temáticas presentes nos artigos que versam sobre a formação docente no campo das políticas educacionais nos últimos três anos, podendo contribuir para novas discussões e produção de conhecimento. Contudo destacamos que esses achados se constituíram a partir de um processo metodológico que possuí as suas especificidades e particularidades, tendo em vista que a pesquisa qualitativa é bastante dinâmica. Desta forma, compreendemos que processos metodológicos distintos podem sinalizar para outros (ou os mesmos) resultados.

\section{Referências.}

ARAÚJO, Gustavo Cunha de; OLIVEIRA, Sabrina Borges de; ALMEIDA, Ludimila Silva. A formação do professor de Arte em Tocantins: velhos desafios e problemas na educação brasileira. Laplage em Revista, Sorocaba. vol.5. n.2. p.176-189, mai.- ago. 2019.

ARNOSTI, Rebeca Possobom; SOUZA NETO, Samuel de. Diálogos entre escola, universidade e literatura de autoajuda - que professor pretendem formar? In:

ANPED - Reunião Nacional 2017. Disponível em:

<http://38reuniao.anped.org.br/sites/default/files/resources/programacao/trabalho_ 38anped_2017_GT08_1149.pdf>. Acesso em 20 jan. 2020.

ASSIS, Alessandra Santos de. Contribuições do pibid para a valorização dos professores: o que dizem as teses e dissertações? In: ANPED - Reunião Nacional 2017. Disponível em:

<http://38reuniao.anped.org.br/sites/default/files/resources/programacao/trabalho_ 38anped_2017_GT08_1256.pdf>. Acesso em 20 jan. 2020.

BARTHO, Viviane Dinês De Oliveira Ribeiro; CLARO, Alessandra Aparecida De Castro. A intrínseca relação entre concepções de língua e atividades didáticas de leitura: contribuições para a formação do professor de língua materna. Forum Lingüístic, Florianópolis. v.15. n. 4. p. 3412 - 3426, out./dez. 2018. 


\section{movim nto \\ programa de pós-graduação \\ faculdade de educação \\ ano 7 - número 14 - Edição Especial - 2020}

<http://38reuniao.anped.org.br/sites/default/files/resources/programacao/trabalho_ 38anped_2017_GT08_534.pdf>. Acesso em 20 jan. 2020.

BELLO, Isabel Melero. Formação, profissionalidade e prática docente: relatos de vida de professores. São Paulo: Arte \& Ciência, 2002.

BEHRING, Elaine Rossetti. Brasil em contra-reforma: desestruturação do Estado e perda de direitos. 2. ed. São Paulo: Cortez, 2008.

CAMPELO, Talita da Silva. Aprendizagem da docência no PIBID: a parceria universidade-escola básica e o desenvolvimento da postura investigativa. In:

ANPED - Reunião Nacional 2017. Disponível em:

$<$ http://38reuniao.anped.org.br/sites/default/files/resources/programacao/trabalho_ 38anped_2017_GT08_53.pdf>. Acesso em 20 jan. 2020.

CANAVIEIRA, Fabiana Oliveira. Militância na educação infantil e formação docente: em busca de um caminho. Laplage em Revista, Sorocaba. vol.4. n.Especial. p.135-147, set.-dez. 2018.

CARVALHO, Rodrigo Saballa de. Práticas de governamento em livros de formação de professores de educação infantil: sensibilidades, disposições e conscientizações em discurso. ETD- Educação Temática Digital, Campinas, SP. v.21. n.1. p.84-104, jan./mar. 2019.

COSTA, Maria Adélia Da; MENESES FILHO, Antônio. Políticas de formação de professores para a Educação Profissional: cem anos de lutas. Ensino Em ReVista, Uberlândia, MG. v.25. n. Especial. p. 1113-1136, 2018.

CUNHA, Cibele Faria; MARCATTO, Flávia Sueli Fabiani. Vestígios de reflexão e autoria nos portfólios produzidos nas/pelas vivências do PIBID/UNIFEI. In:

ANPED - Reunião Nacional 2017. Disponível em:

$<$ http://38reuniao.anped.org.br/sites/default/files/resources/programacao/trabalho 38anped_2017_GT08_929.pdf>. Acesso em 20 jan. 2020.

DOMINSCHEK, Desiré Luciane; ALVES, Tabatha Castro. O PIBID como estratégia pedagógica na formação inicial docente. Rev. Inter. Educ. Sup., Campinas, SP. v. 3 n. 3. p.624-644, set./dez. 2017.

ESTEBAN, Maria Paz Sandín. Pesquisa qualitativa em educação: fundamentos e tradições. Porto Alegre: AMGH, 2010.

FARIA, Denilda Caetano de; SILVA, Moisés Gregório da; ALMEIDA, Maria Zeneide Carneiro Magalhães de. Políticas de expansão da educação superior no Brasil: a formação de professores a distância na UAB. RBPAE. v. 32. n. 3. p. 851 - 870, set./dez. 2016. 


\section{movim nto \\ programa de pós-graduação \\ faculdade de educação \\ ano 7 - número 14 - Edição Especial - 2020}

FELIPE, Eliana da Silva. Repercussões do pacto nacional pela alfabetização na idade certa na formação e profissionalização docente. In: ANPED - Reunião Nacional 2017. Disponível em:

<http://38reuniao.anped.org.br/sites/default/files/resources/programacao/trabalho_ 38anped_2017_GT08_1296.pdf>. Acesso em 20 jan. 2020.

FERREIRA, Eliza Bartolozzi; OLIVEIRA, Dalila Andrade (Org.). Crise da escola e políticas educativas. Belo Horizonte: Autentica Editora, 2009.

FERREIRA, Lúcia Gracia. Desenvolvimento profissional e carreira docente: diálogos sobre professores iniciantes. Acta Scientiarum Education, Maringá. v. 39. n.1. p. 79-89, Jan.-Mar. 2017.

FLICK, Uwe. Introdução a metodologia de pesquisa: um guia para iniciantes. Porto Alegre: Penso, 2013.

FRANCO, Aléxia Pádua; SILVA JÚNIOR, Astrogildo Fernandes da; GUIMARÃES, Selva. Saberes históricos prescritos na BNCC para o ensino fundamental: tensões e concessões. Ensino Em Re-Vista, Uberlândia, MG. v.25. n.Especial. p. 10161035, 2018. Disponível em:

<http://www.seer.ufu.br/index.php/emrevista/article/view/46455/24952>. Acesso em 08 jan. 2020.

GOMES, Marineide de Oliveira. O lugar da formação de professores de educação infantil em cursos de pedagogia: formação menor para o trabalho com crianças pequenas? In: ANPED - Reunião Nacional 2017. Disponível em:

<http://38reuniao.anped.org.br/sites/default/files/resources/programacao/trabalho_ 38anped_2017_GT08_87.pdf>. Acesso em 20 jan. 2020.

GUIMARÃES, Heriédna Cardoso; HENRIQUES, Eda Maria de Oliveira. Um olhar para a construção de sentidos sobre a formação inicial de professores de física do ensino médio. In: ANPED - Reunião Nacional 2017. Disponível em:

$<$ http://38reuniao.anped.org.br/sites/default/files/resources/programacao/trabalho_ 38anped_2017_GT08_235.pdf>. Acesso em 20 jan. 2020.

HANITA, Marília Yuka. Resistência do programa observatório da educação (Obeduc) e desenvolvimento profissional de professores iniciantes. In: ANPED Reunião Nacional 2017. Disponível em:

$<$ http://38reuniao.anped.org.br/sites/default/files/resources/programacao/trabalho_ 38anped_2017_GT08_951.pdf>. Acesso em 20 jan. 2020.

KRAWCZYK, Nora Rut; VIEIRA, Vera Lucia. A reforma educacional na América Latina: uma perspectiva histórico-sociológica. São Paulo: Xamã, 2008. 


\section{movim nto \\ programa de pós-graduação \\ faculdade de educação \\ ano 7 - número 14 - Edição Especial - 2020}

LEAL, Fernanda de Lourdes Almeida; BOITO, Crisliane; LIMA; Maria Betania Barbosa da Silva. Unidade acadêmica de educação infantil da UFCG: espaço de diálogos, construção de saberes e formação docente. Laplage em Revista, Sorocaba. vol.4. n.Especial. p.102-114, set.-dez. 2018.

KURTZ, Fabiana Diniz. Professor como profissional ou agente de políticas de mercado? O papel das tecnologias de informação e comunicação na formação inicial docente sob a perspectiva histórico-cultural. In: ANPED - Reunião Nacional 2017. Disponível em:

$<$ http://38reuniao.anped.org.br/sites/default/files/resources/programacao/trabalho_ 38anped_2017_GT08_803.pdf>. Acesso em 20 jan. 2020.

MARTINS, Bárbara Amaral; SILVA, Rosilaine Cristina da. Formação docente na perspectiva da educação inclusiva: análise de teses e dissertações dos programas de pós-graduação em educação no Brasil._Educação: Teoria e Prática, Rio Claro, SP. vol. 26. n.53. p. 528-549, SETEMBRO-DEZEMBRO. 2016.

MARTINS, Rosana Maria; SOUZA, Ana Paula Gestoso de; OLIVEIRA, Rosa Maria Moraes Anunciato de. Licenciandas em pedagogia e professoras iniciantes: diálogo por meio de narrativas online. In: ANPED - Reunião Nacional 2017. Disponível em:

$<$ http://38reuniao.anped.org.br/sites/default/files/resources/programacao/trabalho 38anped_2017_GT08_680.pdf>. Acesso em 20 jan. 2020.

MARTINS FILHO, Lourival José; SOUZA, Alba Regina Battisti de. PIBID e docência: práticas e cenários. Diálogo, Canoas. n. 33. p. 39-56, dez. 2016.

MICARELLO, Hilda Aparecida Linhares da Silva. A BNCC no contexto de ameaças ao estado democrático de direito. EccoS - Rev. Cient., São Paulo. n. 41. p. 61-75, set./dez. 2016. Disponível em <https://www.redalyc.org/articulo.oa?id=71550055005>. Acesso em 08 jan. 2020.

NEIRA, Marcos Garcia; ALVIANO JÚNIOR, Wilson; ALMEIDA, Déberson Ferreira de. A primeira e segunda versões da BNCC: construção, intenções e condicionantes. EccoS - Rev. Cient., São Paulo, n. 41, p. 31-44, set./dez. 2016. Disponível em: <https://www.redalyc.org/articulo.oa?id=71550055003>. Acesso em 08 jan. 2020.

OLIVEIRA JÚNIOR, Ailton Paulo de; PRATA-LINHARES, Martha Maria;

KARWOSKI, Acir Mário. Formação docente no contexto brasileiro das Instituições Federais de Educação Superior. Ensaio: aval. pol. públ. Educ., Rio de Janeiro. v.26. n. 98. p. 52-90, jan./mar. 2018.

PANIAGO. Rosenilde Nogueira. Aprendizagem da docência no PIBID: possibilidade, tensões e fragilidades. In: ANPED - Reunião Nacional 2017. 


\section{movim nto \\ programa de pós-graduação \\ faculdade de educação \\ ano 7 - número 14 - Edição Especial - 2020}

Disponível em:

<http://38reuniao.anped.org.br/sites/default/files/resources/programacao/trabalho_ 38anped_2017_GT08_70.pdf>. Acesso em 20 jan. 2020.

PINHO, Maria José de; PASSOS, Vânia Maria de Araújo. Complexidade, ecoformação e trandisciplinaridade: por uma formação docente sem fronteiras teóricas. Revista Observatório, Palmas. v. 4. n. 2. p. 433-457, abr-jun. 2018.

RABELO, Francy Sousa. Os espaços não escolares e os desafios da docência em ambiente hospitalar para o/a pedagogo/a em formação. In: ANPED - Reunião Nacional 2017. Disponível em:

$<$ http://38reuniao.anped.org.br/sites/default/files/resources/programacao/trabalho 38anped_2017_GT08_134.pdf>. Acesso em 20 jan. 2020.

RIVELLI, Helena. A pesquisa sobre formação de professores para os usos da avaliação na educação básica no GT08 da Anped no período de 2005-2015. In: ANPED - Reunião Nacional 2017. Disponível em: $<$ http://38reuniao.anped.org.br/sites/default/files/resources/programacao/trabalho 38anped_2017_GT08_741.pdf>. Acesso em 20 jan. 2020.

RODRIGUES, Camila de Oliveira; CARDOSO, Fernanda de Souza. PIBID e o fazer docente na formação inicial de educação física e artes. Caderno de Educação Física e Esporte, Marechal Cândido Rondon. v. 15. n. 2. p. 87-96, jul./dez. 2017.

RODRIGUES, Fabiana de Cássia; COUTINHO, Luciana Cristina Salvatti. Apontamentos sobre educação e trabalho no Brasil contemporâneo: aspectos da contrarreforma educacional. Rev. HISTEDBR On-line, Campinas, v.17, n.3 [73], p.886-905, jul./set. 2017.

RODRIGUES, Priscila Andrade Magalhães; CERDAS, Luciene; PASCHOALINO, Jussara Bueno de Queiroz. Aproximações e propostas de parceria entre universidade e escola na formação de professores: uma análise a partir dos trabalhos apresentados nas últimas cinco edições da anped (2010-2015). In:

ANPED - Reunião Nacional 2017. Disponível em: http://38reuniao.anped.org.br/sites/default/files/resources/programacao/trabalho_3 8anped_2017_GT08_1202.pdf>. Acesso em 20 jan. 2020.

SCARTEZINI, Raquel Antunes. Formação de professores do ensino superior e identidade profissional docente. In: ANPED - Reunião Nacional 2017. Disponível em:

$<$ http://38reuniao.anped.org.br/sites/default/files/resources/programacao/trabalho_ 38anped_2017_GT08_441.pdf>. Acesso em 20 jan. 2020. 


\section{movim nto \\ programa de pós-graduação \\ faculdade de educação \\ ano 7 - número 14 - Edição Especial - 2020}

SILVA, Carla Andréa Lima da. Educação infantil: currículo e autoria docente. Revista Ibero-americana de Educação. vol. 71. p. 87-110, 2016.

SILVA, Melissa Rodrigues da. Articulação escola e universidade: algumas reflexões acerca da formação inicial e continuada para professores da educação básica. In: ANPED - Reunião Nacional 2017. Disponível em:

$<$ http://38reuniao.anped.org.br/sites/default/files/resources/programacao/trabalho_ 38anped_2017_GT08_1161.pdf>. Acesso em 20 jan. 2020.

SOUZA, Edmacy Quirina de; DINIS, Nilson Fernandes. Formação docente, relações étnico-raciais e educação infantil. Laplage em Revista, Sorocaba. vol. n.Especial. p.38-54, set.- dez. 2018.

VIDAL, Eloisa Maia; VIEIRA, Sofía Lerche. Professores da educação básica: perfil e percepções sobre sucesso dos alunos. Est. Aval. Educ., São Paulo. v. 28. n. 67. p. 64-101, jan./abr. 2017.

VIEIRA, Sofia Lerche. Políticas de formação em cenários de reforma. In: VEIGA, IIma Passos Alencastro; AMARAL, Ana Lúcia (Orgs.). Formação de professores: políticas e debates. Campinas, SP: Papirus, 2002.

\section{SOBRE O AUTOR}

ADILSON DE SOUZA BORGES é Mestre em Educação pela Universidade Federal da Fronteira Sul (UFFS), doutorando em Educação na Universidade do Oeste de Santa Catarina (UNOESC), professor de Artes e Música da rede municipal de ensino de Faxinal dos Guedes (SC).

E-mail: adilsonsb@hotmail.com

Recebido em: 14.07.2020

Aceito em: 16.07.2020 